\title{
Dyspnea Associated with Cervical Spondylotic Radiculopathy: A Case Report and Review of Literatures
}

\author{
Soichiro TAKAMIYA, ${ }^{1}$ Toshitaka SEKI, ${ }^{1}$ Kazuyoshi YAMAZAKI, ${ }^{1}$ \\ and Ikuma ECHIZENYA ${ }^{1}$
}

\author{
${ }^{1}$ Department of Neurosurgery, Faculty of Medicine and Graduate School of Medicine, \\ Hokkaido University, Sapporo, Hokkaido, Japan
}

\begin{abstract}
When a patient presents with dyspnea, most physicians immediately associate it with cardiopulmonary diseases but not with the neurologic ones. Dyspnea due to cervical spondylosis rarely occurs, making it under-recognized. We report a case of a 57-year-old man who complained of dyspnea a month after his traffic accident. Chest X-ray showed a left diaphragm elevation, and cervical computed tomography (CT) revealed foraminal stenoses at $\mathrm{C3} / 4, \mathrm{C} 4 / 5$, and $\mathrm{C} 5 / 6$ on both sides, especially C3/4 on the left side. Anterior cervical discectomy and fusion at C3/4 and C4/5 were performed via a standard anterior cervical approach. Foraminal stenoses due to osteophyte were found to be more severe in the left side; therefore, thorough foraminotomies were performed. Titanium-coated polyether-ether-ketone (PEEK) cages filled with an artificial bone graft were inserted into both intervertebral spaces. His dyspnea improved immediately after the operation. Postoperative spirometry showed a gradually improving respiratory function. Therefore, cervical spondylosis should be considered to cause dyspnea, although it is an atypical symptom. Considering previous reports, outcomes achieved with surgical treatment were better than that with conservative therapy for cervical spondylotic radiculopathy-related dyspnea.
\end{abstract}

Keywords: dyspnea, cervical spondylosis, radiculopathy, anterior cervical discectomy and fusion

\section{Introduction}

When a patient presents with dyspnea, most physicians immediately associate it with cardiopulmonary diseases, such as airway constriction or heart failure. However, dyspnea accompanied by diaphragmatic paralysis is suspected to be a phrenic nerve palsy, which may occur due to bronchogenic carcinoma, thoracic/neck surgeries, trauma, infection, or neurologic disease. ${ }^{1)}$ However, involvement of the cervical spinal cord or nerve is seldom considered even though phrenic nerves originate from them. Herein, we report a rare case of cervical spondylotic radiculopathy with dyspnea. Related literatures were reviewed, and the efficacy of their surgical treatments was shown.

Received May 28, 2020; Accepted July 16, 2020

Copyright $\subseteq 2021$ by The Japan Neurosurgical Society This work is licensed under a Creative Commons AttributionNonCommercial-NoDerivatives International License.

\section{Case Report}

\section{History and examinations}

A 57-year-old man was referred to our hospital with dyspnea that started 2 months before his presentation. He had a traffic accident 3 months before presentation and was diagnosed with spinous process fractures from C3 to C6, sternum, and second to fourth ribs on the right side at a previous hospital. At the time, chest X-ray showed no abnormal findings (Fig. 1a). As the pain gradually decreased, he started to complain of dyspnea. His symptom gradually worsened, making it hard to go up the stairs and lie down to sleep. He visited the respiratory medicine and neurology departments of the previous hospital. Chest X-ray and computed tomography (CT) did not show any abnormal findings without elevation of the left diaphragm which was the contralateral side of rib fractures (Fig. 1b), thereby traumatic phrenic nerve palsy was suspected. 

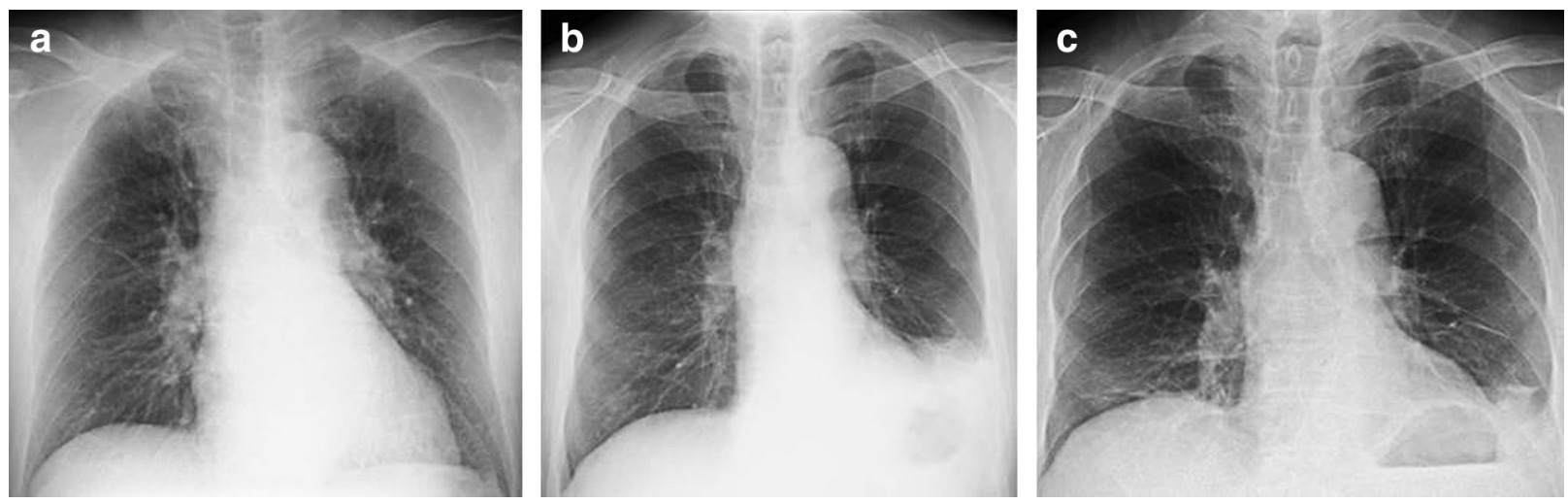

Fig. 1 Chest X-rays immediately after the accident (a), preoperative (b), and postoperative (c). The diaphragm on the left side was elevated preoperatively although no diaphragmatic abnormality was observed immediately after the accident. The diaphragm abnormality was also improved postoperatively.

The patient had no medical history such as cardiopulmonary diseases; however, he was a current smoker. Neurological examination revealed a subtle paresthesia on the right forearm at the radial side as well as dyspnea and no hyperreflexia of the deep tendon reflexes nor spasticity. Flexion-extension views of the cervical X-ray did not show cervical instability. Cervical CT showed foraminal stenoses at $\mathrm{C} 3 / 4, \mathrm{C} 4 / 5$, and $\mathrm{C} 5 / 6$ on both sides, especially C3/4 on the left side (white arrow); however, the spinal canal was not that narrow (Fig. 2a-2c). Cervical magnetic resonance imaging (MRI) revealed mild disk bulging at C3/4, C4/5, and C5/6 without lateralities nor an intramedullary high signal on T2-weighted images (Fig. 2d-2f). Spirometry showed a mixed obstructive and restrictive defect with percent forced vital capacity (FVC) of $68.2 \%$, and forced expiratory volume percent in one second $\left(\mathrm{FEV}_{1.0} / \mathrm{FVC}\right)$ of $56.4 \%$. The latter dysfunction might be caused by smoking. The left phrenic nerve stimulation test ${ }^{2)}$ suggested a low electrical potential. Based on these findings, his symptoms were suspected to be caused by cervical spondylotic radiculopathy at the left $\mathrm{C} 4$.

As the patient's symptom might be triggered by trauma, whether it could be improved or not remains unclear. However, he opted to undergo surgery as no other options were available to resolve the problem. Finally, anterior cervical discectomy and fusion at C3/4 and C4/5 were performed to effectively decompress the nerve roots. The disk level to be operated was determined based on the phrenic nerve anatomy and his symptom of paresthesia on the right forearm.

\section{Operative procedure}

After the induction of general anesthesia, the patient was placed in a neutral supine position. A transverse right-side skin incision was made to expose the C3, C4, and C5 vertebrae via a standard anterior cervical approach. Discectomies and bilateral foraminotomies were performed at each level. Foraminal stenoses due to osteophyte were more severe in the left sides (Supplementary Fig. 1, left; Supplementary Fig. 1 is available online.); therefore, thorough foraminotomies were performed using a bone curette and an ultrasonic aspirator, confirming sufficient root nerve decompressions (Supplementary Fig. 1, right). The posterior longitudinal ligament was excised, and no migrating disc was ensured. Titanium-coated polyether-ether-ketone (PEEK) cages (Mecta-C Cervical Cage; Medacta International, Castel San Pietro, Ticino, Switzerland) filled with an artificial bone graft made of hydroxyapatite and collagen and Refit (Hoya Technosurgical, Tokyo, Japan) were inserted into both intervertebral spaces. Intraoperative somatosensory- and motor-evoked potentials remained stable.

\section{Postoperative course}

No complication or device failures were reported. During the immediate postoperative period, his dyspnea was ameliorated, allowing him to lie down without discomfort. Chest X-ray showed an improved hemidiaphragmatic elevation on the left side (Fig. 1c). Cervical CT proved expansion of each intervertebral foramen (Fig. 2g-2i). Postoperative spirometry also showed a gradually improving respiratory function: the \%FVC became $78.9 \%$ and $\mathrm{FEV}_{1.0}$ /FVC became $64.9 \% 1$ month postoperatively (Fig. 3 ).

\section{Discussion}

Dyspnea is an extremely rare symptom in cervical spondylosis, making it difficult to diagnose alone. 

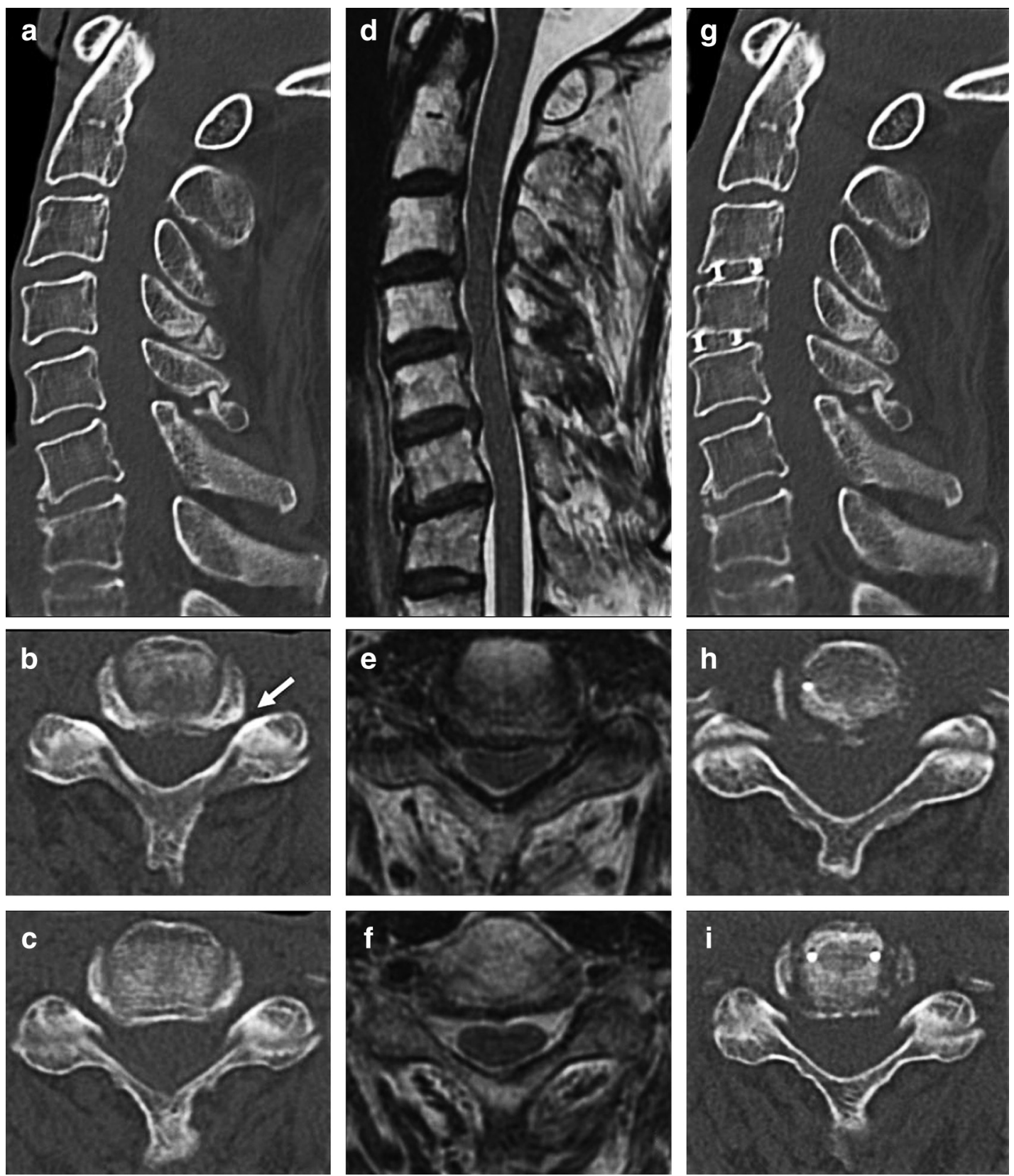

Fig. 2 Preoperative and postoperative findings. Preoperatively, a remarkable spinal canal stenosis did not exist in the sagittal view of cervical CT (a), whereas foraminal stenoses were observed at C3/4 (b), C4/5 (c), and C5/6 on both sides in the axial view. The $\mathrm{C} 3 / 4$ foramen on the left side was especially narrow (white arrow). Cervical MRI revealed mild disc bulging at $\mathrm{C} 3 / 4, \mathrm{C} 4 / 5$, and $\mathrm{C} 5 / 6$ in the sagittal view (d) without an intramedullary high signal on T2-weighted images. It also showed no lateral disc herniations at C3/4 (e), C4/5 (f), and C5/6 in the axial view. Postoperatively, titanium-coated PEEK cages were inserted between $\mathrm{C} 3 / 4$ and $\mathrm{C4} / 5$ (g). Intervertebral foramens were expanded at $\mathrm{C} 3 / 4$ (h) and C4/5 (i). CT: computed tomography, MRI: magnetic resonance imaging, PEEK: polyether-ether-ketone.

To our best knowledge, only 10 cases of phrenic nerve palsy associated with cervical spondylotic radiculopathy exist, including the present case $^{2-10)}$ (Table 1), with nearly the same number of case reports associated with cervical myelopathy, ${ }^{11-19)}$ and some case series showed a declined respiratory function in cervical myelopathy. ${ }^{20,21)}$ Diagnosis of dyspnea associated with cervical spondylotic myelopathy is relatively straightforward because canal stenosis is easy to be recognized on radiological 


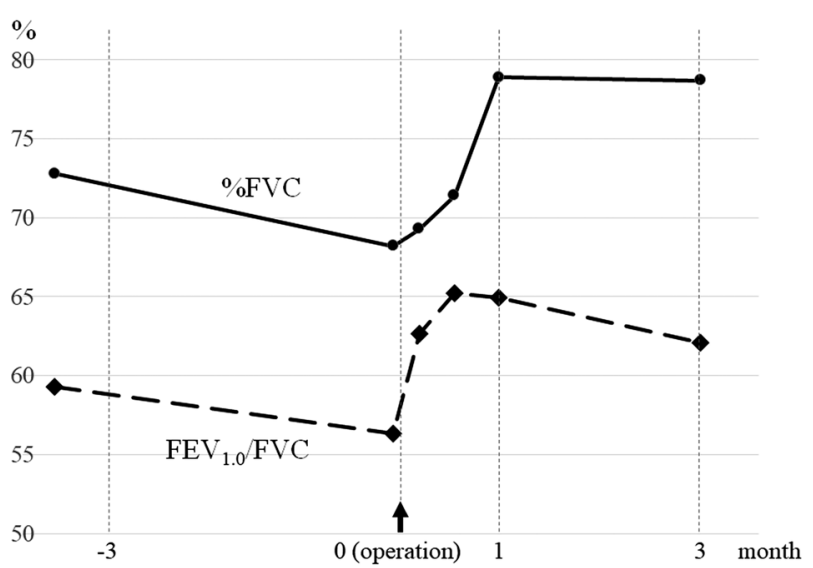

Fig. 3 The respiratory function changes. Both the

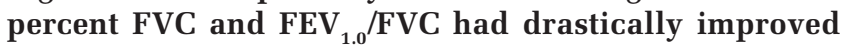
since the operation. $\mathrm{FEV}_{10}$ : forced expiratory volume percent in one second, FVC: forced vital capacity.

studies without paying any special attention and patients with cervical spondylotic myelopathy who complain of a dyspnea generally have other neurological symptoms. In contrast, dyspnea due to spinal nerve compression could be missed, especially if the spinal cord was not severely compressed. Radiological and neurological findings may be subtle as shown in the current case. Indeed, phrenic nerve palsy has been reportedly caused by motor root compression and the phrenic nerve receives its input from the third to fifth cervical nerve roots: the fourth nerve roots provide the main supply and the third/fifth roots are supplemental ${ }^{5,22)}$; however, this fact may not be sufficiently recognized, and their compression is not carefully considered. In addition, no symptoms of the upper extremity usually accompany $\mathrm{C} 4$ radiculopathy, making it difficult to diagnose.

Among reported cases of cervical spondylotic radiculopathy-related dyspnea, there were nine men and one woman. Their mean age was 62.7 (range, 47-87) years. Most of them (9/10) had foraminal stenosis at C3/4 or C4 root compression. Multiple nerve roots were involved in eight cases, including the present case. The present case with severe foraminal stenosis at $\mathrm{C} 3 / 4$ and mild at $\mathrm{C} 4 / 5$; nevertheless, nerve decompressions were performed for both levels based on the following perspectives: (1) decompression of the C5 nerve root partially associated with the phrenic nerve could additionally improve dyspnea and (2) multiple nerve roots were involved and targeted for operation in most reported cases. Seven patients underwent surgical treatments, whereas the others received conservative therapies, such as bilevel airway positive pressure. When improvement is defined as ameliorations of dyspnea and/or respiratory function, all patients who underwent surgery improved, whereas those who did not undergo surgery did not improve. Surgical decompression for dyspnea due to cervical spondylotic radiculopathy tended to improve the symptom compared with conservative therapy statistically (Fisher's exact test, $p=0.0667$ ).

As described above, reports of phrenic nerve palsy with cervical spondylotic radiculopathy are relatively rare. However, such cases might be more potentially observed. O'Beirne et al. ${ }^{23)}$ reported that ipsilateral cervical foraminal stenoses are commonly detected in patients diagnosed with "idiopathic" diaphragmatic paralysis. They also argued that cervical foraminal stenosis may possibly be an underrecognized cause of diaphragmatic palsy. Thus, whether foraminal stenosis exists or not in patients complaining of dyspnea or diaphragmatic paralysis of unknown cause should be carefully considered. In conclusion, we reported a rare case of surgically improved cervical spondylotic radiculopathy with dyspnea. Therefore, cervical spondylosis may cause dyspnea, although it is an atypical symptom, and latent patients may have not been diagnosed yet. Considering previous reports, better outcomes can be achieved with surgical treatment than with conservative therapy for dyspnea included by cervical spondylosis.

\section{Conflicts of Interest Disclosure}

The authors report no conflict of interest associated with this paper. All authors have registered online Self-reported COI Disclosure Statement Forms through the website for JNS members.

\section{References}

1) Piehler JM, Pairolero PC, Gracey DR, Bernatz PE: Unexplained diaphragmatic paralysis: a harbinger of malignant disease? J Thorac Cardiovasc Surg 84: 861-864, 1982

2) Manabe H, Sakai T, Tezuka F, et al.: Hemidiaphragmatic paralysis due to cervical spondylosis: a case report. Spine Surg Relat Res 3: 183-187, 2019

3) Buszek MC, Szymke TE, Honet JC, et al.: Hemidiaphragmatic paralysis: an unusual complication of cervical spondylosis. Arch Phys Med Rehabil 64: 601-603, 1983

4) Cloward RB: Diaphragm paralysis from cervical disc lesions. Br J Neurosurg 2: 395-399, 1988

5) Hayashi H, Kihara S, Hoshimaru M, Hashimoto N: Diaphragmatic paralysis caused by cervical spondylosis. Case report. J Neurosurg Spine 2: 604-607, 2005 


\begin{tabular}{|c|c|c|c|c|c|}
\hline $\begin{array}{l}\text { Author, } \\
\text { Year }\end{array}$ & $\begin{array}{l}\text { Age, } \\
\text { sex }\end{array}$ & Symptoms & Radiological findings & Treatment & $\begin{array}{l}\text { Course of respiratory function } \\
\text { (follow-up period) }\end{array}$ \\
\hline $\begin{array}{l}\text { Buszek } \\
\text { et al., } \\
1983^{3)}\end{array}$ & $67, \mathrm{M}$ & $\begin{array}{l}\text { Shortness of breath } \\
\text { Paracervical pain } \\
\text { bil wrist/finger/shoulder weakness }\end{array}$ & $\begin{array}{l}\text { C3-5 canal stenosis } \\
\text { bil C3/4, C4/5 foraminal steno }\end{array}$ & $\begin{array}{l}\text { C2-6 laminoplasty } \\
\text { with C3/4, C4/5 } \\
\text { foraminotomy }\end{array}$ & Improved (6 weeks) \\
\hline $\begin{array}{l}\text { Cloward, } \\
1988^{4)}\end{array}$ & $47, \mathrm{~F}$ & $\begin{array}{l}\text { Neck, lt arm pain } \\
\text { lt hand numbness } \\
\text { lt arm weakness } \\
\text { Difficulty to sing }\end{array}$ & $\begin{array}{l}\text { C5/6, C6/7 canal stenosis } \\
\text { lt C4/5 disc herniation }\end{array}$ & $\mathrm{C} 4 / 5, \mathrm{C} 5 / 6, \mathrm{C} 6 / 7 \mathrm{ACDF}$ & Improved (ND) \\
\hline $\begin{array}{l}\text { Hayashi } \\
\text { et al., } \\
2005^{5)}\end{array}$ & $64, \mathrm{M}$ & $\begin{array}{l}\text { Nuchal pain } \\
\text { Dyspnea } \\
\text { lt arm weakness } \\
\text { lt arm hypesthesia }\end{array}$ & $\begin{array}{l}\text { C3/4 disc herniation and } \\
\text { thickened ligamentum flavum } \\
\text { C3 retrospondylolisthesis } \\
\text { bil C3/4 foraminal stenosis } \\
\text { C4-C7 osteophytes }\end{array}$ & C3-7 laminoplasty & $\begin{array}{l}\% \text { VC: } 66.6 \% \rightarrow 73.9 \% \\
\text { FEV }_{1.0 \%}: 68.2 \% \rightarrow 67.7 \% \text { (6 weeks) }\end{array}$ \\
\hline $\begin{array}{l}\text { Weiss } \\
\text { et al., } \\
2011^{6)}\end{array}$ & $59, \mathrm{M}$ & $\begin{array}{l}\text { Recurrent pneumonia } \\
\text { Radiating pain }\end{array}$ & lt $\mathrm{C} 2 / 3$, C3/4 foraminal stenosis & $\begin{array}{l}\text { Posterior cervical root } \\
\text { Decompression }\end{array}$ & $\begin{array}{l}\text { improved, no more pneumonia } \\
\text { (10 month) }\end{array}$ \\
\hline $\begin{array}{l}\text { Reddy and } \\
\text { Josephson, } \\
2014^{7)}\end{array}$ & $87, \mathrm{M}$ & $\begin{array}{l}\text { Orthopnea } \\
\text { lt deltoid weakness }\end{array}$ & $\begin{array}{l}\text { bil C2/3, C3/4, C4/5 foraminal } \\
\text { stenosis }\end{array}$ & BiPAP & not improved (over 2 years) \\
\hline $\begin{array}{l}\text { John and } \\
\text { Tavee, } \\
2015^{8)}\end{array}$ & $49, \mathrm{M}$ & $\begin{array}{l}\text { Neck pain } \\
\text { Orthopnea }\end{array}$ & $\begin{array}{l}\text { rt C3/4, C4/5, C5/6, lt C6/7 } \\
\text { Foraminal stenosis }\end{array}$ & BiPAP & $\begin{array}{l}\% \text { VC: } 41 \% \rightarrow 59 \% \\
\mathrm{FEV}_{1.0 \%}: 71.5 \% \rightarrow 76.3 \% \\
(6 \text { months) } \\
\text { residual mild orthopnea } \\
\text { (9 months) }\end{array}$ \\
\hline $\begin{array}{l}\text { Keelan } \\
\text { et al., } \\
2017^{9)}\end{array}$ & $63, \mathrm{M}$ & $\begin{array}{l}\text { bil shoulder and neck discomfort } \\
\text { Orthopnea }\end{array}$ & $\begin{array}{l}\text { C5/6 canal stenosis } \\
\text { C } 4 / 5, \text { C5/ } 6 \text { disc bulging } \\
\text { bil C3/4, C4/5 foraminal } \\
\text { stenosis }\end{array}$ & $\begin{array}{l}\text { BiPAP } \\
\text { Posterior foraminotomies }\end{array}$ & $\begin{array}{l}\text { not improved (ND) } \\
\text { FVC: } 3.88 \mathrm{~L} \rightarrow 4.86 \mathrm{~L}\end{array}$ \\
\hline $\begin{array}{l}\text { Singleton } \\
\text { et al., } \\
2018^{10)}\end{array}$ & $64, \mathrm{M}$ & $\begin{array}{l}\text { Shortness of breath } \\
\text { Intermittent neck pain }\end{array}$ & rt C3/4, C4/5 foraminal stenosi & & $\begin{array}{l}\mathrm{FEV}_{1.0 \%}: 62.9 \% \rightarrow 64.4 \% \\
(3 \text { months })\end{array}$ \\
\hline $\begin{array}{l}\text { Manabe } \\
\text { et al., } \\
2019^{2)}\end{array}$ & $70, \mathrm{M}$ & $\begin{array}{l}\text { lt arm pain } \\
\text { bil hands numbness } \\
\text { bil deltoids and rt biceps weakness } \\
\text { Radicular pain (rt C5 dermatome) } \\
\text { Hypoesthesia (below C5 dermatome) }\end{array}$ & $\begin{array}{l}\text { C3 retrospondylolisthesis } \\
\text { C3/4 canal stenosis } \\
\text { C3/4, lt C4/5 foraminal stenosis }\end{array}$ & $\begin{array}{l}\text { C4 laminoplasty } \\
\text { +rt C3/4 foraminotomy } \\
\text { +lt C4/5 foraminotomy } \\
\text { +C2-5 posterior fusion }\end{array}$ & $\begin{array}{l}\% \text { VC: } 90.2 \% \rightarrow 102.6 \% \\
\text { FEV }_{1.0 \%}: 72.5 \% \rightarrow 72.3 \% \text { (10 days) }\end{array}$ \\
\hline $\begin{array}{l}\text { Present } \\
\text { case, } 2020\end{array}$ & $57, \mathrm{M}$ & $\begin{array}{l}\text { Dyspnea } \\
\text { lt arm numbness }\end{array}$ & $\begin{array}{l}\text { lt } \mathrm{C} 3 / 4 \text {, bil C5/6 foraminal } \\
\text { stenosis } \\
\text { C3/4, C4/5 mild disc bulging }\end{array}$ & $\mathrm{C} 3 / 4, \mathrm{C} 4 / 5 \mathrm{ACDF}$ & $\begin{array}{l}\% \text { VC: } 68.2 \% \rightarrow 78.7 \% \\
\text { FEV }_{1.0 \%}: 56.4 \% \rightarrow 74.0 \% \\
\text { (3 months) }\end{array}$ \\
\hline
\end{tabular}

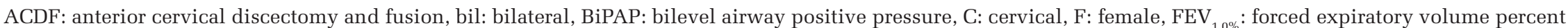
in one second, FVC: forced vital capacity, lt: left, M: male, ND: not described, rt: right, \% VC: percent vital capacity. 
6) Weiss C, Witt T, Grau S, Tonn JC: Hemidiaphragmatic paralysis with recurrent lung infections due to degenerative motor root compression of C3 and C4. Acta Neurochir (Wien) 153: 597-599, 2011

7) Reddy YN, Josephson RA: Osteoarthrosis causing altered mental status: a case report. J Med Case Rep 8: 401, 2014

8) John S, Tavee J: Bilateral diaphragmatic paralysis due to cervical chiropractic manipulation. Neurologist 19: 65-67, 2015

9) Keelan E, Kidney J, Judge EP: An unusual case of orthopnea. Clin Med (Lond) 17: 245-247, 2017

10) Singleton N, Bowman M, Bartle D: Resolution of right hemidiaphragm paralysis following cervical foraminotomies. Case Rep Orthop 2018: 6195179, 2018

11) Parke WW, Whalen JL: Phrenic paresis-a possible additional spinal cord dysfunction induced by neck manipulation in cervical spondylotic myelopathy (CSM): a report of two cases with anatomical and clinical considerations. Clin Anat 14: 173-178, 2001

12) Daniil ZD, Malagari K, Zakynthinos EG, Kapotsis GE, Roussos C, Papiris SA: An unusual cause of dyspnea in a 77-year-old man. Chest 125: 770-774, 2004

13) Fregni F, Conceicao Souza GE, Taricco MA, Mutarelli EG: Phrenic paresis and respiratory insufficiency associated with cervical spondylotic myelopathy. Acta Neurochir (Wien) 146: 309-312; discussion 312, 2004

14) Vengust R, Mihalic R, Turel M: Two different causes of acute respiratory failure in a patient with diffuse idiopathic skeletal hyperostosis and ankylosed cervical spine. Eur Spine J 19: S130-134, 2010

15) Lin HY, Chen CC, Lee YK, Su YC: Dyspnea caused by atlantoaxial subluxation in a patient with rheumatoid arthritis. Case Rep Emerg Med 2012: 170956, 2012
16) Jin Y: An aged patient with 11-year untreated progressive atlantoaxial subluxation manifesting with dyspnea due to unilateral diaphragmatic paralysis: a case report and literature review. Aging Clin Exp Res 26: 677-680, 2014

17) $\mathrm{Yu}$ E, Romero N, Miles T, Hsu SL, Kondrashov D: Dyspnea as the presenting symptom of cervical spondylotic myelopathy. Surg J (NY) 2: e147-e150, 2016

18) Mondal A, Giri PP: Cervical myelopathy in a child: a rare cause of hypoventilation syndrome presenting with type 2 respiratory failure. Indian J Crit Care Med 22: 303-305, 2018

19) Nishida T, Ishiguro T, Ota $C$, et al.: Restrictive ventilatory impairment improved by laminoplasty for ossification of the posterior longitudinal ligament. Clin Case Rep 7: 284-288, 2019

20) Ishibe T, Takahashi S: Respiratory dysfunction in patients with chronic-onset cervical myelopathy. Spine (Phila Pa 1976) 27: 2234-2239, 2002

21) Toyoda H, Nakamura H, Konishi S, Terai H, Takaoka K: Does chronic cervical myelopathy affect respiratory function? J Neurosurg Spine 1: 175-178, 2004

22) Hollinshead WH, Keswani NH: Localization of the phrenic nucleus in the spinal cord of man. Anat Rec 125: 683-699, 1956

23) O’Beirne SL, Chazen JL, Cornman-Homonoff J, Carey BT, Gelbman BD: Association between diaphragmatic paralysis and ipsilateral cervical spondylosis on MRI. Lung 197: 727-733, 2019

Corresponding author: Soichiro Takamiya, MD Department of Neurosurgery, Faculty of Medicine and Graduate School of Medicine, Hokkaido University, North 15 West 7, Kita-ku, Sapporo, Hokkaido 001-0015, Japan.

e-mail: soichiro.tkmy@gmail.com 